\title{
A INFLUÊNCIA DO AMBIENTE SOCIOMORAL SOBRE AS PRÁTICAS DE BULLYING EM SALA DE AULA
}

\author{
Poliana Soares Quinato Zocoler ${ }^{1,}$ Jaqueline Batista de Oliveira Costa ${ }^{2}$ \\ ${ }^{1}$ Graduada em Pedagogia pela Universidade do Oeste Paulista/UNOESTE. ${ }^{2}$ Docente do Curso de Pedagogia da Universidade do \\ Oeste Paulista/UNOESTE).e-mail: poliana.soares@gmail.com
}

\begin{abstract}
RESUMO
Nos dias atuais, muito tem se falado sobre violência na escola. Dentre as diferentes modalidades de violência que se manifestam intramuros escolares, a prática do bullying vem se destacando nos últimos anos. Nesse sentido, a presente pesquisa teve como objetivo geral discutir a influência do ambiente sociomoral sobre as práticas de bullying na sala de aula. Especificamente buscamos caracterizar o fenômeno bullying enquanto modalidade específica de violência; discutir a prática do bullying sob o contexto das relações sociomorais estabelecidas dentro da escola; compreender como as relações sociomorais estabelecidas entre os pares de alunos são capazes de influenciar a prática do bullying. A investigação foi realizada em uma escola pública estadual do município de Presidente Prudente (SP). Participaram do estudo 40 alunos do $6^{\circ}$ ano do Ensino Fundamental entre 10 e 11 anos de idade. Foi utilizado como instrumento para coleta de dados, a aplicação de dois questionários respondidos pelos alunos. $\mathrm{O}$ questionário de número 01 teve como objetivo identificar como os sujeitos investigados avaliam o ambiente sociomoral de suas salas de aula; o questionário de número 02 buscou identificar a ocorrência e a intensidade de prática do bullying na escola, bem como o envolvimento dos sujeitos, quer como vítimas, perpetradores e/ou espectadores. Os dados, obtidos por meio dos dois questionários, receberam tratamento qualiquantitativo, por meio do qual, as respostas dos investigados foram cruzadas com o intuito de identificar a possível relação do ambiente sociomoral da sala de aula e a intensidade da prática de bullying pelos alunos.
\end{abstract}

Palavras chave: Bullying. Escola. Ambiente Sociomoral. Sala de aula.

\section{THE INFLUENCE OF ENVIRONMENT ON SOCIAL MORAL PRACTICES OF BULLYING IN THE CLASSROOM}

\begin{abstract}
Today, much has been said about violence in school. Among the different types of violence that manifest Intra School, bullying has been highlighted in recent years. In this sense, this research aimed to discuss the influence of environment on the sociomoral practices of bullying in the classroom. Specifically we seek to characterize the phenomenon of bullying as a specific form of violence, to discuss bullying in the context of relationships established within the school sociomorais; sociomorais understand how the relationships established between students pairs are able to influence the practice of bullying. The investigation was performed in a public school in the city of Presidente Prudente (SP). Participants were 40 students in the 6 th grade of elementary school between 10 and 11 years of age. Was used as an instrument for data collection, the application of two questionnaires answered by students. The number 01 questionnaire aimed at identifying how the subjects investigated sociomoral evaluate the environment of their classrooms, the number 02 questionnaire sought to identify the occurrence and intensity of bullying at school as well as the involvement of individuals, either as victims, perpetrators and / or spectators. The data obtained by means of two questionnaires, received treatment quantitative quali, whereby the responses of those investigated were crossed in order to identify the possible relationship between the environment of the classroom sociomoral and intensity of bullying by students.
\end{abstract}

Keywords: Bullying. School. Socio moral environment. Classroom. 


\section{INTRODUÇÃO}

A agressividade e a violência escolar, segundo Fante (2005), vêm apresentando um aumento significativo nos últimos anos, o que tem acarretado um constante patrulhamento policial nas escolas, decorrente da gravidade dos atos praticados em seu interior. Dentre as diferentes modalidades de violência que se manifestam intramuros escolares, a prática do bullying vem se destacando.

Entretanto, segundo Silva (2010), o bullying não é prioridade das escolas brasileiras, uma vez que se trata de um problema que atinge o mundo todo, sendo encontrado em toda e qualquer escola, e não se restringindo a nenhum tipo de instituição, seja ela infantil, fundamental, média, pública ou particular, rural ou urbana. Pode-se dizer que as escolas não admitem a ocorrência do bullying entre seus estudantes ou não têm conhecimento sobre o assunto. Dessa forma, se negam a enfrentá-lo, levando crianças e adolescentes a, muitas vezes, não falarem sobre o que está ocorrendo consigo e a achar que eles são culpados por tais agressões.

Nesse sentido esta proposta de pesquisa pretende contribuir com os estudos que vem sendo desenvolvidos, por inúmeros pesquisadores, sobre a temática em questão.

A relevância do estudo justifica-se pela grande destruição que o bullying é capaz de provocar na vida das vítimas, espectadores e, mesmo dos perpetradores. Sabemos que o problema tende a se agravar, caso medidas emergenciais de combate e prevenção, envolvendo toda a comunidade escolar, não sejam implementadas. Entretanto, para sabermos lidar com o problema, é necessário que conheçamos suas múltiplas determinações. Assim, questionamos: O ambiente sociomoral da escola, baseado em práticas e relações interpessoais coercitivas ou cooperativas, exerce alguma influência sobre a prática do bullying entre os alunos?

Nesse sentido, a presente pesquisa tem como objetivo geral discutir a influência do ambiente sociomoral sobre as práticas de bullying na sala de aula. Especificamente pretendemos caracterizar o fenômeno bullying enquanto modalidade específica de violência; discutir a prática do bullying sob o contexto das relações sociomorais estabelecidas dentro da escola; compreender como as relações sociomorais estabelecidas entre os pares de alunos são capazes de influenciar a prática do bullying.

\section{BULLYING: O QUE É E COMO SE MANIFESTA}

Segundo Cezar (2010), estudos realizados mostram que, até algum tempo atrás, atitudes agressivas como "xingar", bater, não eram considerados como violência pela maioria dos educadores e pais, pois ao seus olhos essas atitudes eram consideradas como simples brincadeiras entre os estudantes. Hoje é sabido que estas atitudes realizadas de forma repetitiva e intencional caracterizam o bullying.

O termo Bullying é de origem inglesa sem tradução para o português. Segundo Silva (2010), Cezar (2010), Fante (2005), Lopes Neto (2005), a expressão bullying corresponde a uma série de atitudes violentas que podem ser físicas ou psicológicas, sempre recorrentes, ou seja, aplicada de forma repetitiva por um agressor/autor contra uma vitima/alvo incapaz de se defender, causando dor e angústia aos envolvidos.

Ainda para Abramovay e Rua (2003): "Bullying é definido como abuso físico ou psicológico contra alguém que não é capaz de se defender" (p.23).

Olweus (1998) define o bullying:

Como um conjunto de atitudes agressivas, intencionais e repetitivas, adotado por um ou mais alunos contra outro(s), 
sem motivação evidente, causando dor, angústia e sofrimento. É caracterizado por sua natureza repetitiva e por desequilibro de poder. Insultos, intimidações, apelidos cruéis e constrangedores, gozações que magoam profundamente, acusações injustas, atuação de grupos que hostilizam, ridicularizam e infernizam a vida de outros alunos, a ponto de excluí-los do grupo, além de danos físicos, morais e materiais. (apud CESAR, 2010, p. 66).

De acordo com Fante (2005) as manifestações do bullying correspondem a:

Insultos, intimidações, apelidos cruéis, gozações que magoam profundamente, acusações injustas, atuação de grupos que hostilizam, ridicularizam e infernizam a vida de outros alunos levando-os à exclusão, além de danos físicos, morais e materiais, são algumas das manifestações

do comportamento bullying. (2005, p. 29).

\section{A PRÁtICA DO BULLYING NA ESCOLA: VÍTIMAS, AUTORES, ALVOS E ESPECTADORES}

Para Lopes Neto (2005) e Cezar (2010), os papeis desempenhados na prática do bullying podem assim ser classificados entre: autores, alvos, alvos/autores e espectadores de bullying.

Segundo Lopes Neto (2005), o aluno que é exposto repetidas vezes, às ações de perpetradores (agressores) de forma negativa, por um ou mais alunos, é uma vítima. Dessa forma, entende-se que, para ser caracterizado como bullying, essas ações negativas serão aplicadas repetidas vezes, unicamente com 0 intuito de humilhar, perseguir, incomodar outra pessoa, de forma intencional.

O perfil psicológico das vítimas mostra que as mesmas são inseguras, tímidas, pouco sociáveis, com baixa autoestima. Sendo assim, não se sentem preparadas para combater a violência sofrida. Normalmente as vitimas sofrem caladas, sem pedir ajuda à escola ou mesmo à família.

Os alunos normalmente são
frágeis fisicamente ou
apresentam alguma "marca" que
as destaca da maioria dos
alunos: são gordinhas ou
magras demais, altas ou baixas
demais; usam óculos; são
"caxias". [...] enfim, qualquer
coisa que fuja ao padrão
imposto por um determinado
grupo pode deflagrar o processo
de escolha da vítima do bullying.
(SILVA, 2010, p. 38).

Segundo Silva (2010), o agressor de bullying possui em seu perfil "traços de desrespeito e maldade". Silva enfatiza ainda que Os agressores apresentam desde muito cedo, "aversão às normas, não aceitam ser contrariados ou frustrados, geralmente estão envolvidos em pequenos delitos. [...] o desempenho escolar desses jovens costuma ser regular ou deficitário, sem que isso configure deficiência intelectual ou de aprendizagem" (p. 43).

Para Cezar (2010), alvos de bullying que, por vezes sofrem agressões, passam a perpetrar as agressões sofridas contra outras pessoas que são consideradas mais fracas. Por não conseguirem lidar com as provocações recebidas, "descontam" em outras pessoas. E assim, o aluno que é um alvo de provocações, faz novos alvos perpetrando as crueldades já conhecidas.

Lopes Neto (2005) pondera que a maioria dos alunos, não se envolve nos casos de bullying, pelo menos não diretamente. Todavia, os alunos que testemunham a ação dos agressores em suas vitimas (denominados para objeto de estudo como espectadores/testemunhas das ações de bullying), normalmente se calam e não interferem, pois o medo de ser a "próxima vitima", de não saber a quem recorrer, faz com que silenciem e não apontem os agressores. 
Ainda segundo Lopes Neto (2005), "grande parte das testemunhas sente simpatia pelos alvos, tende a não culpá-los pelo ocorrido, condena o comportamento dos autores e deseja que os professores intervenham mais efetivamente". (2005, p. 168).

\section{DESENVOLVIMENTO MORAL DA CRIANÇA E AMBIENTE SOCIOMORAL}

Afim de melhor compreender sobre desenvolvimento moral da criança, bem como sobre a possível relação entre ambiente sociomoral da escola e a prática do bullying entre os alunos, baseamos a pesquisa na Psicologia moral de Jean Piaget, contida no livro O Juízo Moral na Criança (1994) e de outros teóricos que dão continuidade a seus estudos como, Tognetta (2005), Menin (1996), Vinha (1999), dentre outros.

Para Menin (1996), ao analisar sobre o que é moral, pode-se tentar buscar respostas sobre o conceito ainda no século XVIII com filósofo alemão Emanuel Kant que se dedicou a pensar nas seguintes perguntas: o que seria a moral? Ou ainda o que seria agir moralmente bem ou mal? Ou se agir moralmente bem seria o mesmo que apenas seguir as regras que nos cercam?

Menin (1996) resume as conclusões de Kant observando que agir moralmente bem não é o mesmo do que seguir as regras sociais, porque se assim o fosse, não precisaríamos da moral, pois ao seguir esta ou aquela regra/lei estabelecida socialmente eu agiria corretamente, mas a moral exige um princípio universal que é diferente de apenas seguir os costumes desta ou daquela sociedade.

Sendo assim a moral deve indicar o que é bom, certo, errado pra "o maior número de pessoas possível, ou ainda, para toda e qualquer pessoa deste mundo, em qualquer lugar"
(MENIN, 1996, p.38) e não apenas para um pequeno grupo de pessoas com seus costumes.

Menin (1996) enfatiza que:

O que o filósofo está nos dizendo é que para sermos moralmente corretos basta agirmos de acordo com motivos racionais que concordemos (possamos querer) que sejam motivos possíveis para toda e qualquer pessoa! Ou, de modo bem simples: "o que pode valer para mim devo concordar que possa valer para todos!". (MENIN, 1996, p.38).

Para Piaget (1994) o indivíduo passará por duas etapas morais. Nascemos na anomia, que é a total ausência de regras; a criança não reconhece as regras e baseia suas relações em sua vontade imediata e ainda não tem a consciência do que é permitido ou não através das regras.

Posteriormente a criança atingirá a moral heterônoma. Esta se baseia na moral autoritária, na relação de coação, unilateral, na qual a criança apenas obedece às regras impostas, sem questioná-las, apenas as segue por medo de sanções punitivas ou ainda de perder o amor de um adulto responsável, como pais e professores.

$\mathrm{Na}$ autonomia moral as relações, segundo Piaget (1994), são baseadas no cooperativismo, no respeito e diálogos mútuos. Nesta fase o indivíduo segue as regras não porque são impostas, mas sim porque ao analisar a importância de seguir as mesmas, consideram certas em sua visão. É neste ponto que entendem e internalizam valores morais que nortearão suas ações/relações em sociedade.

Para Piaget (1994) é na interação e troca diárias com o meio social, que o indivíduo constrói os valores morais. Neste meio se encontra inserida a família, a escola e as diferentes pessoas que o constitui.

Ainda segundo Piaget (1994), não é nas "lições morais" que a criança construirá valores, 
pois ninguém ensina o outro a agir desta ou daquela maneira e a seguir esta ou aquela regra moral. Mas, é na troca de experiências que a criança irá internalizar valores que the serão significantes, de acordo com os seus princípios.

Importante ressaltar que Piaget (1994)

afirma que nenhum indivíduo será totalmente heterônomo ou autônomo, mas que durante sua vida, uma moral ou outra serão mais visíveis. Sendo assim, não são estágios fixos.

Dessa forma, se faz necessário discutir se ambientes escolares coercitivos, onde as relações são unilaterais e o professor é autoritário e baseia suas ações em mecanismos coercitivos, favorece a prática do bullying entre os estudantes.

Ao passo que, em uma sala de aula onde as relações são cooperativas, as regras são estabelecidas em conjunto, com alunos e professores dialogando a fim de resolver possíveis conflitos, a prática do bullying tende a desaparecer. O fato das relações serem estabelecidas de forma democrática permite aos alunos resolver os conflitos por meio do diálogo e do respeito mútuo.

Para Tognetta (2005), quando pensamos os conflitos, a palavra por si só, denota, violência, brigas entre os envolvidos. Porém é necessário que se pense o conceito de conflitos sob a ótica de que é exatamente mediante os conflitos, desde que, resolvidos através do diálogo, de forma cooperativa, que poderemos viver melhor em sociedade e, neste caso, dentro do ambiente escolar.

Sendo assim, o conflito pode ser 0 caminho para que os indivíduos aprendam a conviver de forma harmoniosa com o outro, desde que sejam entendidos, dentro do ambiente escolar, como um degrau para estabelecer relações mais solidárias.

Segundo Vinha (1999) a qualidade das relações existentes dentro de sala de aula, bem como a troca de experiências entre os colegas de classe e com os professores interfere na construção de valores pelo indivíduo. Sendo assim, consideramos de suma importância, a caracterização do ambiente sócio moral, a fim de compreendermos como ocorrem essas relações e suas possíveis consequências na identidade moral do aluno.

\section{AMBIENTE SOCIOMORAL COERCITIVO}

Para Piaget (1994), sendo em seu meio social, lugar este, onde a criança irá construir valores morais através das interações e trocas diárias com esse meio, a sala de aula nos parece o ambiente propício para tal. E mais, é na sala de aula que é possível, dependendo das relações estabelecidas neste espaço, favorecer a autonomia moral do aluno ou ainda fazê-lo permanecer na heteronomia. Sendo assim, se a sala de aula caracterizar-se com um ambiente sociomoral coercitivo, a moral heterônoma irá prevalecer; do contrário, se na sala de aula a cooperação predominar, a moral autônoma encontrará ambiente propício para florescer.

Para Vinha (1999), o ambiente (sala de aula) coercitivo é aquele onde as relações estabelecidas são unilaterais, o que pressupõe que o professor sendo uma figura mais forte se comporta de forma autoritária, não permitindo que seus alunos expressem seus questionamentos e opiniões. Há regras que são pré-estabelecidas pelo professor e devem ser seguidas pelos alunos, mediante punições caso não sejam respeitadas.

\section{AMBIENTE SOCIOMORAL COOPERATIVO}

Para Vinha e Tognetta (2009), o ambiente cooperativo será aquele onde as relações estabelecidas em sala de aula, se pautam na cooperação, solidariedade, diálogo e respeito mútuos. O professor age com a autoridade que 
Ihe cabe, entendendo que agir com autoridade e ser autoritário são duas expressões diferentes.

Para Tognetta (2005), os conflitos em um ambiente cooperativo são vistos pelo professor de forma natural, pois é no conflito e na resolução destes através da interação entre os pares, ambiente este favorecido pelo professor que trabalha com os alunos ações como o diálogo, a capacidade de aceitar outro ponto de vista - que será construído um ambiente que favoreça a autonomia dos alunos.

Neste ambiente cooperativo é possível observar que as relações desenvolvidas em sala de aula são democráticas, afetuosas, onde o conflito não significa indisciplina, mas sim, oportunidade de melhorar o relacionamento entre os pares e professor. Verifica-se neste caso que o ambiente favorece para que o aluno saia da moral heterônoma e se torne realmente autônomo.

De acordo com Piaget (1994), a troca existente entre o indivíduo e o meio ambiente favorece para a autonomia ou ainda a permanência da heteronomia do sujeito.

\section{METODOLOGIA}

Trata-se de uma pesquisa qualitativa do tipo estudo de caso. Conforme Minayo (2007, p. 21), na pesquisa qualitativa o pesquisador "[...] trabalha com o universo dos significados, dos motivos, das aspirações, das crenças dos valores e das atitudes, o que corresponde ao espaço mais profundo das relações, dos processos e dos fenômenos humanos". Nesse sentido, o ambiente escolhido para a investigação constitui-se a fonte direta de coleta de dados e o pesquisador deve ter uma relação dinâmica com o(s) sujeito(s) para uma melhor interpretação dos fenômenos que serão pesquisados.

A investigação foi realizada em uma escola pública estadual do município de Presidente Prudente (SP), logo após aprovação do projeto pelo Comitê de Ética e Pesquisa da
Universidade do Oeste Paulista (Protocolo n.1112/12). Participaram do estudo 40 alunos do 60 ano do Ensino Fundamental entre 10 e 11 anos de idade. Foi utilizada como instrumento para coleta de dados, a aplicação de dois questionários (Questionário 01 e 02) respondidos pelos próprios sujeitos. O questionário de número $01^{1}$ teve como objetivo identificar como os sujeitos investigados avaliam 0 ambiente sociomoral de suas salas de aula; o questionário de número $02^{2}$ buscou identificar a ocorrência e a intensidade de prática do bullying entre os alunos, bem como o envolvimento dos sujeitos, quer como vítimas, perpetradores e/ou espectadores.

Os dados, obtidos por meio dos dois questionários, receberam tratamento qualiquantitativo e as respostas dos investigados foram cruzadas com o intuito de identificarmos a possível relação do ambiente sociomoral da sala de aula e a intensidade da prática de bullying pelos alunos.

A análise dos resultados poderá ser observada nos próximos itens.

\section{RESULTADOS}

O questionário de número 01 , contendo treze questões de múltipla escolha, buscou compreender a visão que os alunos possuem do ambiente sociomoral de suas salas de aula. Assim, foi questionado primeiramente, sobre quem estabelece as regras em sala de aula. Dos 40 alunos entrevistados, $57,5 \%$ afirmaram que as regras são estabelecidas apenas pelo professor, outros $37,5 \%$ que as regras são estabelecidas pela professora junto com os alunos; apenas $5 \%$ destacam que é a direção da escola que

\footnotetext{
1 Questionário elaborado pelas autoras, tendo como embasamento teórico a Psicologia do desenvolvimento moral de Jean Piaget e seguidores.

${ }^{2}$ Questionário utilizado pela instituição inglesa Kidscape que há anos se dedica ao tema bullying. Foi elaborado para ser aplicado nas escolas. Está disponível no site: www.kidscape.org.uk.
} 


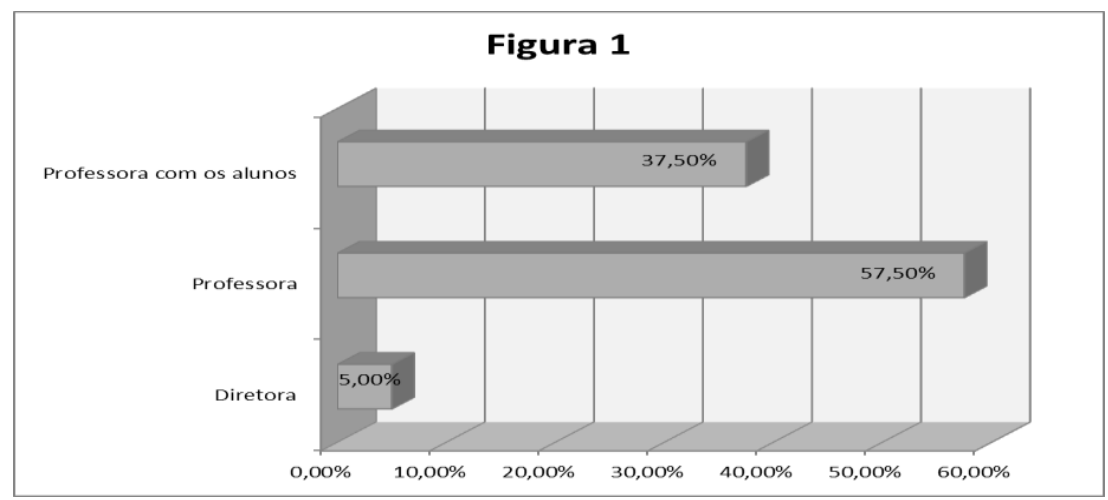

Figura 1. quem estabelece as regras em sala de aula

Ao serem questionados se concordam com as regras existentes $90 \%$ afirmaram que sim e $10 \%$ alegam que concordam apenas com algumas das regras.

Quando questionados acerca do por que obedecem as regras $72,5 \%$ responderam que acreditam que as regras são importantes para a boa convivência da turma, $20 \%$ alegam segui-las para agradar a professora e $7,5 \%$ obedecem por medo de ser castigados.
A maioria dos alunos afirmou que as situações de violência que ocorrem com maior frequência em sala de aula são: desrespeito entre os pares $(31,25 \%)$; agressões verbais e/ou físicas $(28,75 \%)$; mentira $(17,5 \%)$; desrespeito por parte da professora para com os alunos e dos alunos contra a professora (10,0\% respectivamente) e roubos entre alunos (2,5\%). Abaixo segue gráfico com todas as respostas citadas pelos sujeitos da pesquisa.

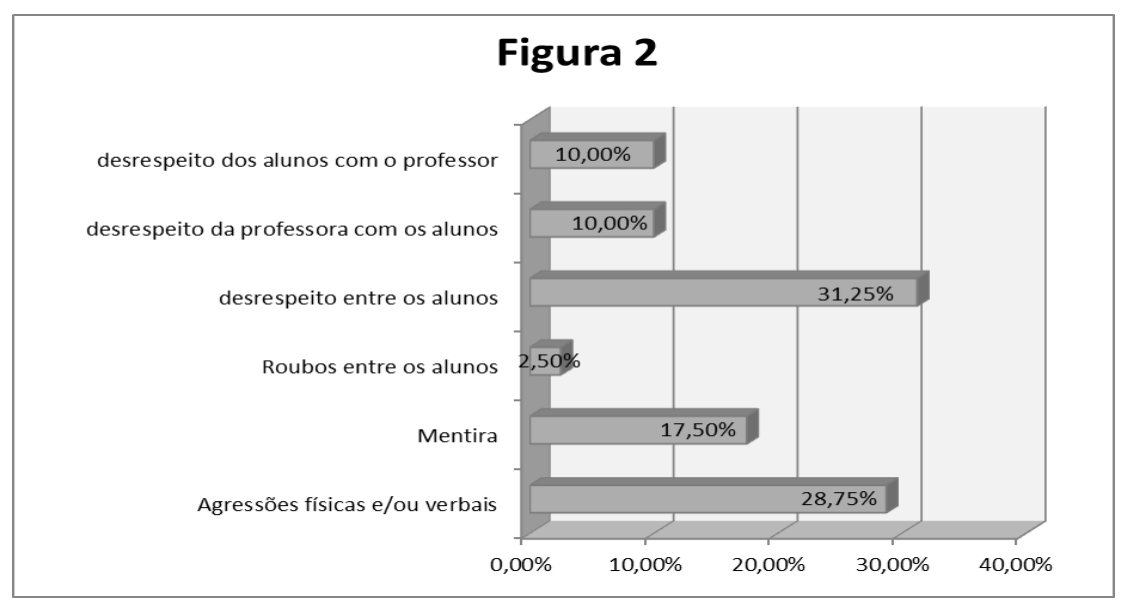

Figura 2. Qual dessas situações ocorrem com maior frequência em sala de aula

Os alunos foram questionados sobre como sua professora resolve os conflitos em sala de aula envolvendo violência. Para essa questão cada indivíduo poderia apresentar duas respostas. Conforme $39,74 \%$ dos sujeitos, a resolução dos conflitos é feita por meio de encaminhamento dos envolvidos para a diretoria; $32,05 \%$ dos docentes chamam os pais ou responsáveis para conversar; $10,26 \%$ afirmam que a professora coloca os envolvidos para fora 
da sala; $10,0 \%$ busca dialogar com os envolvidos

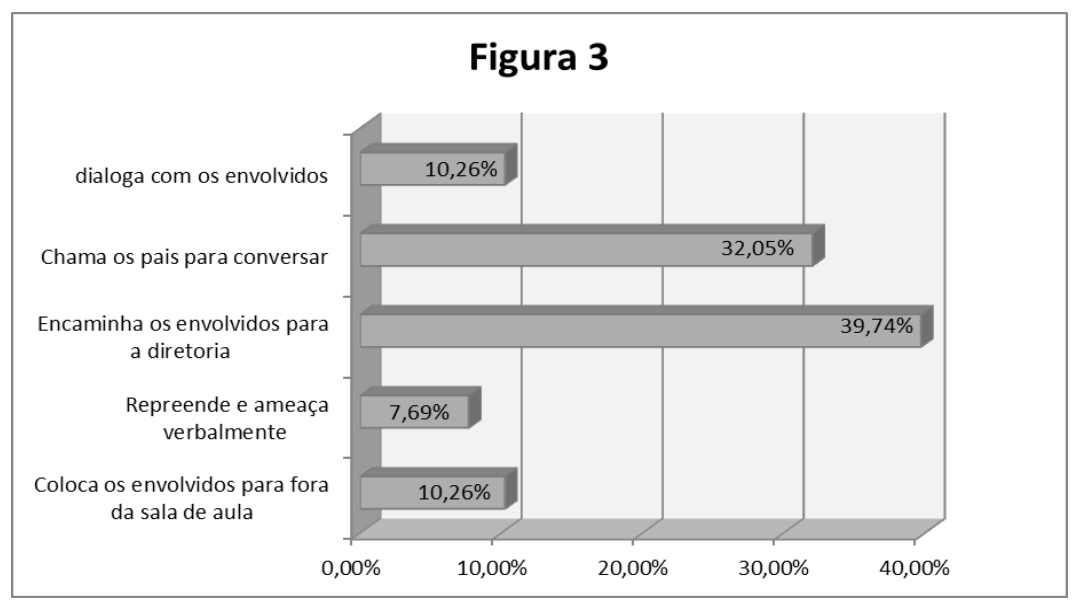

Figura 3. Como a professora resolve os conflitos em sala de aula

Do total de alunos que responderam a questão anterior, $70 \%$ concordam com as medidas adotadas pela professora em situação de conflitos e $30 \%$ dizem concordar apenas em algumas vezes. Nenhum aluno discordou dos encaminhamentos dados pela professora.

Com relação a como agem quando observam que algum colega faz algo considerado errado, $57,5 \%$ afirmaram que fingem não ver, $27,5 \%$ que conversam com seu colega sobre o ocorrido e $15,0 \%$ omitem a informação ao professor por receio de que seu colega seja punido.

Ao serem questionados sobre a relação estabelecida durante a aula com seu professor $42,55 \%$ responderam ficar sentados e ouvirem as explicações do professor; $27,66 \%$ copiam a lição da lousa em silêncio; 10,64\% fazem atividades individuais; $8,51 \%$ fazem atividades em grupo e, do total de alunos entrevistados, apenas $10,64 \%$ afirmaram que existe um tempo durante as aulas para conversarem sobre suas vidas fora da escola.

Para identificar especificamente a ocorrência e a intensidade de prática do bullying na escola, bem como o envolvimento dos sujeitos, foi aplicado um segundo questionário (número 02) padronizado pela instituição inglesa Kidscape aos participantes do estudo. Do total de entrevistados, $67,50 \%$ afirmaram nunca ter sofrido algum tipo de intimidação, agressão ou assédio e 32,5\% disseram já ter sofrido algum tipo de intimidação ou agressão entre 5 a 11 anos de idade (ver fig. 04).

Dentre os que afirmam ter sido vitimizados $\quad(32,5 \%), \quad 46,15 \% \quad$ sofreram intimidações nos últimos seis meses. Destes, $61,54 \%$ afirmam ter sofrido agressão apenas uma vez e $30,77 \%$ por diversas vezes. 


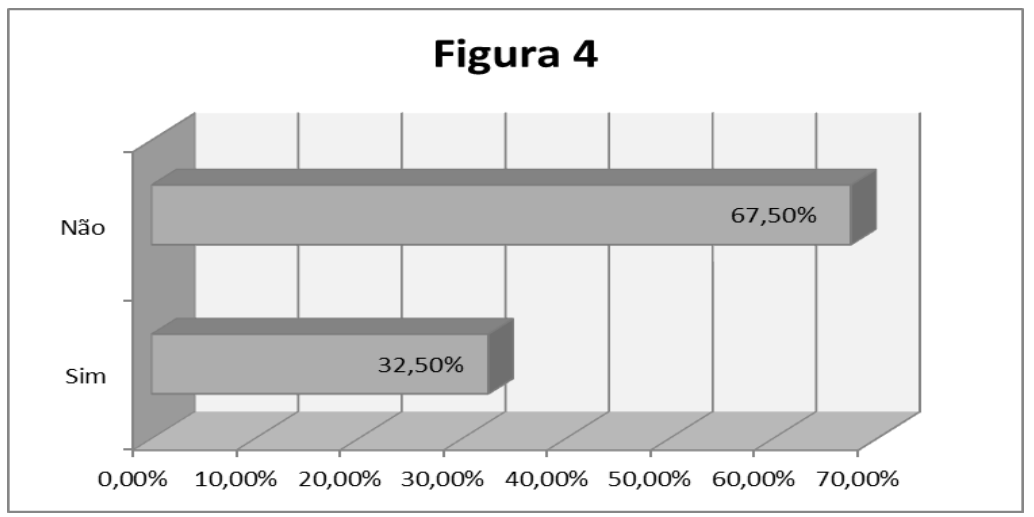

Figura 4. Você já sofreu algum tipo de intimidação, agressão ou assédio?

Quando questionados acerca do que pensam sobre quem pratica intimidação, agressão ou assédio na escola, 62,5\% disseram não gostar das pessoas que praticam estas ações, 17,5\% disseram sentir pena deles e apenas $10 \%$ disseram gostar dos agressores.
A sala de aula e o pátio foram apontados $30,77 \%$, respectivamente, como locais onde aconteceram essas agressões; $23,08 \%$ indicaram outros locais.

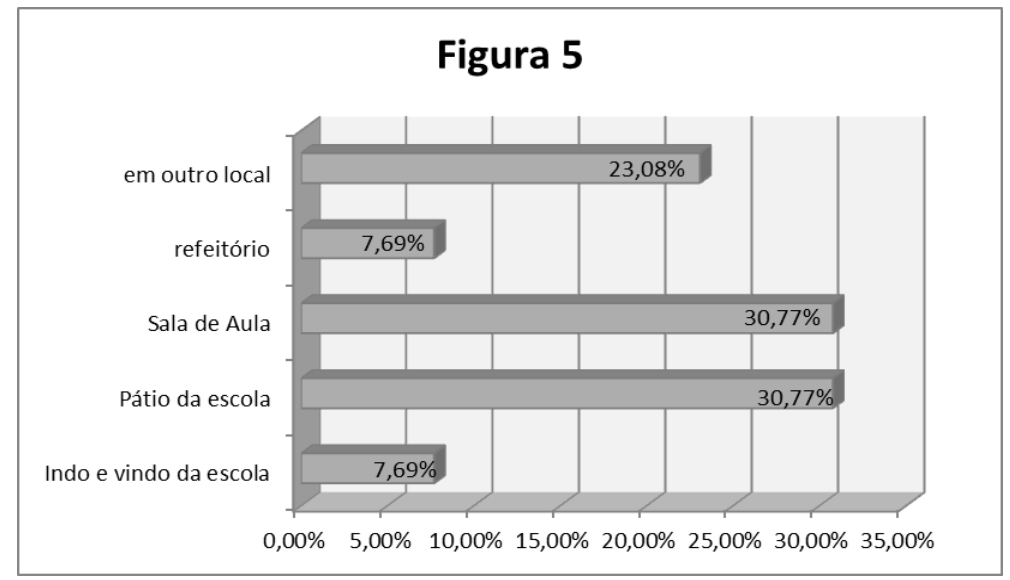

Figura 5. Local onde aconteceram as agressões.

Dos alunos que sofreram alguma agressão (32,50\%), 46,15\% afirmaram que sentiram medo e $23,08 \%$ disseram que não se incomodaram.

Por fim, quando questionados em relação à consequência dessa agressão sofrida $61,54 \%$ dos alunos disseram que não teve consequências e $38,46 \%$ tiveram algumas consequências ruins.

\section{DISCUSSÃO DOS RESULTADOS}

Para Piaget (1994) é na interação e troca diárias com o meio social, que o indivíduo constrói os valores morais. Neste meio se encontra inserida a família, a escola e as diferentes pessoas que o constitui. Sendo assim, consideramos importante analisar como são as relações estabelecidas entre os alunos e destes com os professores.

Segundo Vinha (1999), a qualidade das relações existentes dentro de sala de aula, bem como as trocas de experiências entre os colegas 
de classe e com os professores interfere na construção de valores pelo indivíduo. Neste ponto podemos discutir conceitos como ambiente sociomoral coercitivo e ambiente sociomoral cooperativo.

O primeiro questionário continha perguntas que buscavam identificar a relação sociomoral que era estabelecida entre os pares de alunos e destes com seus professores. Para isso foram levantadas questões tais como: quem estabelece as regras em sala de aula; se os alunos concordavam com as regras existentes; o porquê de seguirem ou não as regras; as situações diárias que ocorriam com maior frequência no tempo escolar; como a professora resolvia possíveis situações de conflitos; se eles concordavam com essas soluções encontradas pela professora e como eles gostariam que fossem as aulas.

As respostas dadas a primeira questão corrobora com as definições de Vinha (1999) que aponta que, em um ambiente de sala de aula coercitivo prevalecerá interações sociais unilaterais, o que pressupõe que o professor sendo uma figura mais forte se comporta de forma autoritária, não permitindo que seus alunos expressem seus questionamentos e opiniões. Há regras que são pré-estabelecidas pelo professor e devem ser seguidas pelos alunos, mediante punições caso não sejam respeitadas. Essa afirmação corrobora com o resultado encontrado no questionário, no qual $57,5 \%$ dos alunos afirmaram que as regras são estabelecidas apenas pela professora. Ao serem questionados se concordavam com essas regras $90 \%$ afirmaram que sim, porém quando questionados por quê? Obtivemos respostas como:

"porque a gente tem que respeitar quem dá as regras" "sim porque a professora tem uma certa sabedoria"

"porque é pra manter a organização" "porque se não tiver regras os alunos tomam conta"

Embora estes alunos concordassem com as regras, parece não haver uma reflexão crítica sobre as mesmas. Os alunos demonstraram entender que as regras existem para serem seguidas, não cabendo a eles questionarem. $O$ intuito das mesmas seria o de manter a classe quieta e em ordem.

Deixam ainda mais evidente tal suposição quando apresentam o porquê seguem as regras, pois, embora tenham afirmado $(72.5 \%)$ que era para a boa convivência da turma, a maioria destes acreditam que a boa convivência se resume a ordem em sala de aula. Sob a perspectiva da teoria do desenvolvimento moral de Piaget (1994) estas crianças (ou préadolescentes) revelam uma tendência predominante da moral heterônoma, na qual a obediência as regras resulta de uma atitude de temor em relação à autoridade constituída. Nesse sentido há uma relação de coação, unilateral, na qual a criança apenas obedece às regras impostas, sem questioná-las e as segue por medo de sanções punitivas ou ainda de perder o amor de um adulto responsável, como pais e professores. Isto fica claro na resposta dada pelos alunos de que seguiam as regras apenas para agradar a professora (20\%).

Com relação a resolução de conflitos, a maioria respondeu que a professora soluciona os conflitos ocorridos em sala de aula encaminhando os alunos envolvidos para a diretoria $(39,74 \%)$ e chamando os pais ou responsáveis para conversar sobre o ocorrido (32,05\%). Como vimos estas ações reforçam, ainda mais, a moral heterônoma dos alunos, pois não permitem que através do diálogo coletivo os mesmos tornem-se capazes de solucionar os conflitos.

De acordo com Tognetta (2005) é através do conflito que sabemos quem somos e o que almejamos, além de sermos capazes de nos 
colocar no lugar do outro. Sendo assim, o conflito pode ser o caminho para que os indivíduos aprendam a conviver de forma harmoniosa com o outro. Desde que sejam entendidos, dentro da escola como um degrau para estabelecer relações mais solidárias, nas quais mostro quem sou, mas também sei respeitar o espaço do outro, o conflito servirá para que seja possível alcançar a autonomia moral.

Sendo assim, em concordância com Vinha (1999), observamos que quando os professores adotam como medidas de resolução ou prevenção de conflitos, transferir a responsabilidade para a diretoria ou os pais, eles tolhem os alunos de buscar dialogar e encontrar meios de solucionar os conflitos entre eles, tornando-os dependentes e submissos e, consequentemente, heterônomos.

Mudar essa realidade não é fácil, mas o caminho a seguir talvez possa ser apontado pelos próprios alunos. De acordo com as suas respostas quando questionados sobre como gostariam que fossem as aulas, $27,27 \%$ gostariam que as aulas fossem mais práticas com menor tempo sentados copiando lição, ou ainda, $15,91 \%$ gostariam que houvesse maior tempo para conversas sobre outros assuntos, curiosidades e não somente sobre a lição da professora.

Esse cenário converge com as propostas apresentadas pelos Parâmetros Curriculares Nacionais - PCNs (BRASIL, 2006), que nos aponta que o caminho a seguir na busca da construção de moral autônoma por parte dos alunos passa, necessariamente, pelas atividades em grupos, experiências fora da sala de aula e que estas ações são capazes de criar um ambiente saudável tanto para a aprendizagem quanto para a resolução de conflitos. Para tanto seria necessário trabalhar os conflitos transversalmente como proposto nos PCNs (BRASIL, 2006).
Com relação especificamente ao Bullying, por meio do segundo questionário aplicado aos alunos podemos discutir alguns pontos. Primeiramente, assim como aponta Fante (2005), a agressividade e a violência escolar vêm apresentando um aumento significativo nos últimos anos, o que tem acarretado um constante patrulhamento policial nas escolas, decorrente da gravidade dos atos praticados em seu interior. Com isso é importante ressaltar que a prática do bullying entre os alunos se caracteriza apenas como uma das modalidades de violência praticadas na escola, portanto nem toda violência sofrida ou praticada poderá ser caracterizado como bullying. Consideramos essa diferenciação importante para que não se banalize o termo.

Verificamos de acordo com o questionário respondido, que do total de alunos entrevistados, apenas $32,50 \%$ disseram já ter sofrido alguma intimidação, assédio ou agressão. Porém destes, $61,54 \%$ afirmaram ter sofrido as agressões apenas uma vez. Ora, se o bullying se caracteriza exatamente pelo caráter repetitivo das agressões, os alunos nos mostram por meio das respostas dadas ao questionário que nem toda agressão poderá ser considerada bullying.

Para Cesar (2010), o fenômeno bullying é singular porque se diferencia de outras formas de violência observadas no cenário escolar. Este se diferencia exatamente porque as ações violentas perpetradas por um ou mais alunos são atitudes repetitivas e intencionais. Ainda é possível confirmar tal hipótese, pois, destes $32,50 \%$ que afirmaram já ter sido alvo de agressão, 61,54\% afirmaram que as agressões não geraram consequências negativas.

Sendo assim legitimam a afirmação de alguns estudiosos do tema, de que nem toda agressão sofrida no ambiente escolar pode se traduzir como bullying. Portanto, é necessário maior conhecimento e reflexão sobre a prevenção e o combate do fenômeno. 
Retomando o objetivo geral desse estudo que consistia em discutir a possível influência do ambiente sociomoral sobre as práticas de bullying na sala de aula, pode-se inferir que, aparentemente, não há uma relação direta entre ambiente sociomoral e a prática do bullying especificamente, pois embora os alunos envolvidos na pesquisa denunciem que 0 ambiente de sua sala de aula seja coercitivo e, consequentemente demonstrem uma forte tendência para moral heterônoma, destacam que seu envolvimento, com a prática do bullying, é insignificante. Contudo acredita-se que embora não tenha sido possível relacionar o ambiente sociomoral da sala de aula com a prática do bullying é provável que as relações sociomorais que se estabelecem nessa escola estejam favorecendo outras modalidades de violência, destacadas pelos próprios alunos.

Convém ressaltar ainda que embora o ambiente sociomoral não influencie a prática de bullying, as observações assistemáticas realizadas no período de coleta dos dados, bem como os comentários dos próprios participantes do estudo, deixam evidentes que as relações interpessoais têm favorecido o florescimento de conflitos que nem sempre são tratados de maneira construtiva. Desse modo, o ambiente sociomoral, provavelmente, tem propiciado a permanência dos estudantes na moral heterônoma.

\section{CONCLUSÃO}

Com esta pesquisa buscou-se compreender se o ambiente sociomoral é capaz de influenciar na prática de bullying em sala de aula. De acordo com as respostas apontadas pelos alunos, levantamos uma discussão necessária à prática educativa que evidencia que o professor tem um papel relevante na construção da almejada autonomia moral dos alunos. A este profissional compete à tarefa de influenciar positiva ou negativamente o ambiente sociomoral da sala de aula, bem como as relações interpessoais entre os alunos e com os próprios professores.

Se o professor favorecer um ambiente sociomoral cooperativo, pensando no grupo, nos diálogos e regras justas irá influenciar na criação de um ambiente capaz de promover a construção da autonomia moral por parte dos alunos e estes, saberão que são capazes de resolver conflitos de forma solidária, de se colocar no lugar do outro, sendo, portanto, tolerante às diferenças individuais, sem que para isso busquem, como resolução de conflitos, a prática da violência.

Desse modo, a educação deverá, além dos conteúdos curriculares, ser capaz de promover a paz, a cooperação, o respeito mútuo, a solidariedade e as trocas de experiências. Ao fazer isto será capaz de garantir a formação de cidadãos moralmente autônomos.

\section{REFERÊNCIAS}

ABRAMOVAY, M.; RUA, M. das G. Violências nas escolas. Brasília: Pitágoras Unesco, 2003.

BRASIL. Ministério da Educação e Cultura. Parâmetros Curriculares Nacionais: Temas Transversais. Brasília: MEC, 2006.

CEZAR, N. Bullying: Preconceito, Estigmas e desafios da educação para a paz. 2010. Dissertação (Mestrado) - Universidade Federal de Mato Grosso

FANTE, C. Bullying escolar: perguntas e respostas. Porto Alegre: Artmed, 2008.

FANTE, C. Fenômeno Bullying: como prevenir a violência das escolas e educar para a paz. 2. ed. rev. e ampl. Campinas/SP: Verus, 2005.

LOPES NETO, A. A. Bullying: comportamento agressivo entre estudantes. Jornal de Pediatria, Porto Alegre, v. 81, n. 5, nov., 2005.

MENIN, M. S. de S.. Desenvolvimento Moral. In. MACEDO, L. de (Org.). Cinco Estudos de Educação Moral. São Paulo: Casa do Psicólogo, 1996. 
MINAYO, M. C. de S.. Pesquisa Social: Teoria, método e criatividade. 26. ed Petrópolis, RJ: Vozes, 2007.

PIAGET, J.. 0 juízo Moral na criança. São Paulo: Summus, 1994.

SILVA, A.B. B. Bullying: mentes perigosas na escola. Rio de Janeiro: Objetiva, 2010.

TOGNETTA, L. R. P.. Construindo a Autonomia Moral na Escola: os conflitos interpessoais e a aprendizagem dos valores. Revista Diálogo Educacional. Curitiba: v. 9, n. 28, p. 525-540, set./dez., 2009. Disponível em: <http://www2.pucpr.br/reol/index.php/dialogo> Acesso em: 20 mar. 2012.

TOGNETTA, Luciene Regina Paulino. Educação dos sentimentos: um caminho para a paz. Revista de Educação do Cogeime. v. 14, n. 27. dez., 2005.

VINHA, Telma Pileggi. 0 educador e a moralidade infantil numa perspectiva construtivista. Campinas (SP), n. 14, julho, $1999 . \quad$ Disponível em: $<$ http://www.bibliotecadigital.unicamp.br/document /?code=vtls000121495 > Acesso em 15 abr. 2012. 